\title{
UM VÍCIO CHAMADO MENTIRA: ENSAIO PSICOLÓGICO SOBRE O MITÔMANO E AS CAUSAS E AS CONSEQUÊNCIAS DA COMPULSÃO POR MENTIR EM SEU COTIDIANO
}

André Luis CLARO ${ }^{1}$

${ }^{1}$ Discente do curso de Psicologia, Universidade do Vale do Rio Verde, UNINCOR

Três corações (MG) - Brasil. Tel: (35) 88679931 - E-mail: aclaro3131@ yahoo.com.br

Recebido em: 01/05/2014 - Aprovado em: 30/06/2014 - Disponibilizado em: 30/07/2014

Resumo: Mentir é, invariavelmente, preciso para se viver em sociedade. E se começa a mentir cedo, ainda quando criança, mas sem maiores prejuízo. Agora, se a mentira para dada pessoa se torna uma compulsão e perdura, chegando ao ponto de as pessoas mais íntimas lhe perderem a confiança, apenas resta se tratar. Para tanto, revelar quais as causas desse vício e suas consequências é o intuito desse trabalho. De maneira coloquialmente embasada em dados empíricos e científicos de autores e profissionais consagrados são levantadas questões, a fim de se desfragmentar os aspectos desse vício. Mas isso não é o ponto de chegada, algo definitivo para o assunto, apenas o ponto de partida.

Palavras-chave: Mentira. Compulsão. Vício.

\section{A ADICTTION CALLED LIE: PSYCHOLOGICAL ASSAY ON MYTHOMANIAC AND THE CAUSES AND CONSEQUENCES OF COMPULSION LIE IN YOUR DAILY LIFE}

\begin{abstract}
Lying is invariably need to live in society. And if you start lying earlier, even as a child but no major damage. Now, if given the lie to person becomes a compulsion and endures to the point of the most intimates you lose confidence, it only remains to treat. To do so, revealing the causes and consequences of this addiction is the aim of this work. So colloquially grounded in empirical data and scientific author and renowned professionals questions are raised in order to defragment the aspects of this addiction. But that is not the point of arrival, something definite to the subject, only the starting point.
\end{abstract}

Keywords: Lie. Compulsion. Addiction.

\section{Introdução}

Não de maneira consciente, as pessoas convivem com o temor da morte, se chafurdam nos mecanismos de defesa do autoengano e da autoilusão para tornar menos "dolorosas" essa vida e a certeza única do fato de que morrerão, serão excluídas desse mundo e, portanto, terão de desapegar à força das coisas e dos outros. Ainda que se tente sabotar esse temor o tolhendo, o transferindo, numa troca inconsciente pelo medo de que algo - que não consiga especificar ou nem seja justificado - não lhe dê certo àquele dia, de que seja demitido, abandonado pela esposa, uma amizade da infância se rompa. Essa transferência pode se dar também ainda que contrariamente aos seus desejos mergulhando no trabalho, esforçando por lisonjear a pessoa amada ao passo que aceita suas incongruências, se absorvendo sobremaneira em um jogo. Por trás disso tudo está o medo da morte. Pois, um cão quando escapa para a rua, volta à calçada ao perceber um carro devido ao seu instinto, porque ainda é meramente levado pela lei da sobrevivência, onde o - maior -, o mais forte - deve ser temido - respeitado. Ao contrário do ser humano, dificilmente esse cão desenvolverá um medo - propriamente da morte - de 
atravessar a rua ainda que não haja um veículo vindo.

\section{Becker diz:}

Não queremos admitir que somos fundamentalmente desonestos no que se refere à realidade, que não controlamos realmente nossas próprias vidas. Não queremos admitir que não ficamos sozinhos, que sempre nos apoiamos em algo que nos transcende, certo sistema de ideias e poderes no qual estamos mergulhados e que nos sustenta. Esse poder nem sempre é óbvio: não precisa ser um deus ou uma pessoa mais forte, mas pode ser o poder de uma atividade que exija plena dedicação, uma paixão, a dedicação a um jogo, um modo de vida que, como uma teia confortável, mantém a pessoa apoiada e ignorante a respeito de si própria e ao fato de que ela não se apoia em seu próprio centro. Todos nós somos levados a sobreviver de uma maneira desinteressada, ignorando quais as energias que realmente consumimos e que tipo de mentira criamos a fim de vivermos segura e serenamente.

Não obstante, há aquelas pessoas que sentem culpa por terem nascido. Não o mero fato de se estar existindo estritamente de uma maneira biológica a partir de um derrame delirante de esperma, mas no caso de se ver como um ser onde aquilo, o nascer, não o torna algo pronto - ainda que feito, concebido - então ele tem que dar à luz a si mesmo, se recompor continuamente para se tornar algo dando um significado perante a si mesmo e, pior no caso do mitômano, diante do inevitável e indelével significado incomensurável do mundo. Emil Cioran bem ponderou:

Nós não corremos em direção à morte; fugimos da catástrofe do nascimento, agitamo-nos como sobreviventes que procuram esquecê-lo. O medo da morte é apenas a projeção no futuro de um medo que remonta ao primeiro instante. Repugna-nos, claro está, chamar flagelo ao nascimento; não inculcaram em nós que era ele o supremo bem, que o pior se situava no fim e não no início da nossa carreira? O mal, o verdadeiro mal, está, porém atrás, e não à nossa frente [...]

[...] Desde que estou no mundo - este desde parece-me carregado de um significado tão assustador que se torna insuportável.

Precisa-se encontrar um caminho próprio em meio a outros idênticos milhões que foram e são seguidos sem pisar nas mesmas pegadas. Seria mais fácil e "justo" já ter vindo ao mundo como os outros vieram: cada um com sua cruz ou consolação. Um sujeito mitômano se vê como o único despojado de seu quinhão ou mesmo infortúnio e se culpa por isso como se tivesse feito algo para merecê-lo, alias não merecê-lo, não ter um caminho a seguir que precisaria simplesmente ser sustentando ou ainda um 
que tenha de ser arrombado. É um nada. Qual maior punição senão a de vir ao mundo como único que terá de se virar para chegar sem nunca ter tido de onde partir? O que fez para aquilo? Esse questionamento perturba esse sujeito dia após dia.

\section{Como nasce a mentira e como se torna um vício}

Até aqui, porém, nada de diferente do que já foi repetido antes por outros autores infinitamente mais doutos do que eu.

A questão é que algumas pessoas se detêm mais ou apenas no temor da morte e vão lutando para se tornar algo para o outro, para no fim morrer apenas de corpo, as lembranças de suas irrefutáveis contribuições para o mundo os farão vivos na lembrança de outrem. Procuram se tornar um novo Leonardo da Vinci, Joana D'Arc ou Kurt Cobain a fim de que seus inevitáveis defeitos sejam aceitos incondicionalmente, tenham sempre muitas pessoas os reverenciando, pois creem que isso esvaecerá a inadequada criação completamente severa ou totalmente frouxa oferecida pelos pais, tornará imaculada a desajustada e angustiante adaptação desses sujeitos no mundo.

Novamente vou me ater a Becker:

Não importa se o sistema de heroísmo de uma cultura é francamente mágico, religioso e primitivo ou secular, científico e civilizado. É, de qualquer forma, um sistema de heróis mítico, no qual as pessoas se esforçam para adquirir um sentimento básico de valor, para serem especiais no cosmo, úteis para a criação, inabaláveis quanto ao seu significado.

Por outro lado, há aqueles que se ocupam de irem dizimando a culpa por terem nascido nada - e para nada além da morte -, irem se satisfazendo com o fato de poderem julgar então justo assim terem vindo ao mundo, pois têm algum livre arbítrio para se constituírem como bem prover.

Outros, por sua vez, invertem esses polos em dados momentos da vida, literalmente os interpolam, em algumas ocasiões tão intensamente conflituosas, que correm o risco de recaírem, por exemplo, num transtorno bipolar. O problema, aqui, reside no fato de que no caso do mitômano, essas duas vertentes o comprimem esmagadoramente o tempo todo e o autoengano e autoilusão inerentes para dissimular o medo da morte tal como a culpa por ter nascido são - e têm de ser para que o indivíduo consiga alguma forma de sobrevivência - potencializados e o efeito é uma euforia paralisante como quem ingere ansiolítico juntamente com doses de álcool.

A culpa por se sentir nada ante a esse "assustador" significado do mundo junto dessa previsão pessimista de que nunca se conseguirá ser alguma coisa equivalente ao que já está aí - e aqui ainda não trato de um hipervalor para suplantar a morte, o que 
somente poderá ocorrer se superada a etapa do nascer - traz um sentimento de inutilidade - o que nomearam de autoestima baixa e seu aprofundamento em longo prazo depressão.

Em vez de terem um estímulo para fazer algo, romper alguma coisa que lhes perturbe, apenas se estarrecem excitantemente diante dos pensamentos que criam uma realidade para si mesmos. Esses pensamentos é aquilo que os preceituam a como agir, bem como lhes alivia um pouco a força dos dois polos que se atraem e se repelem. É assim que se dá o início do vício da mentira, mais precisamente, aqui, o da mitomania.

\section{Benilton Bezerra exemplifica a} respeito da necessidade da mentira na infância:

[...] é o momento, onde o bebê, que desde sempre ouve palavras sem saber que aqueles sons têm significação, começa aos poucos a compreender que aqueles sons e ruídos ou gestos, se os pais são surdos e falam língua de sinais, que aquelas coisas que o atingem carregam significação. E essa passagem de um mundo onde as coisas têm sentido, mas não tem uma significação, as coisas têm uma orientação, mas não tem algo que pode ser questionado, pode ter sua significação posta em questão que é o que a linguagem possibilita, há um momento onde isso começa acontecer. A criança começa a usar palavras e há o momento preciso, onde ela começa a dizer eu, onde ela começa a se designar na primeira pessoa, é um momento complexo e que dura um certo tempo, no qual a criança vai ao mesmo tempo se constituindo como eu e constituindo os outros como eu. E um ponto fundamental desse processo, por exemplo, é onde a criança começa a mentir. A mentira é uma grande conquista no desenvolvimento individual porque, porque a mentira supõe a percepção de que eu tenho um mundo que é indevassável, só é acessível ao outro se eu o revelo, e, portanto, os outros também. A idea de um mundo de que me é próprio e a idea de que os outros também têm um mundo que é próprio é o que constitui esse primeiro momento, esse momento inaugural da constituição de si como eu e que torna possível a mentira. Ao mesmo tempo em que torna possível o início do sentimento de responsabilidade em relação ao outro e da moralidade $[\ldots]$

Mas tal como é necessário abandonar esse estágio da falsa segurança provinda da mentira para se lançar no mundo onde a criança por si mesma tem que ser capaz de se nutrir de novas expectativas. E aí que ela se vê ante o cru do ter nascido pior do que "era" - o nada - e o indefensável morrer que não a levará de volta ao melhor que "antecede" o nascimento, e pode não recuar, recuar algumas vezes ou sempre para esse estágio primitivo e uterino que pode ser explicitado através do Sentimento Oceânico - descrito por Freud -, o qual abordarei mais adiante.

Desse modo, o mitômano segue catexiando - procurando não restringir cada 
dia mais seu repertório verbal e não verbal, se apoiando na "dedicação" a algo. Vai ampliando seus episódios excessivos em relação ao álcool, juntamente aos da mentira. Mas há outros meios de se compensar a realidade, como recorrer à masturbação, ao amor platônico. Assim, toda noite, dar continuidade à sua história de amor criada há alguns dias. Invariavelmente transformando uma vizinha em sua mulher "ideal" ao invés de enfrentar a "real".

Não obstante, tais tramas rocambolescas não são suficientes para sublimar sua libido, então o sujeito apela mais intensa e frequentemente a uma e outra mentira, ainda que esteja oniricamente consciente de que mente, a princípio, não sabe que sabem ou, no mínimo que desconfiam da veracidade, autenticidade do que lhes diz.

O mitômano invariavelmente possui um círculo de amigos restrito, embora em alguns casos esse círculo seja extenso não deixa de ser superficial, seu círculo de amizades pode consistir em um animal de estimação e uns poucos amigos virtuais. Embora não se veja desse modo. Esse sujeito com compulsão por mentir não percebe que nunca consegue - como a maioria absoluta de nós - agir como falava, embora se apresente, infinitamente de forma mais aguda que os demais sujeitos, como se conseguisse tamanha autenticidade.

De acordo com Danilo Marcondes:

Uma sentença expressa um "pensamento" (conteúdo), que é o que se mantém na tradução, e é nisto que consiste seu sentido, porém não sua referência. Em "a estrela da manhã é iluminada pelo sol" e é nisto que consiste seu sentido, porém não sua referência. Em "a estrela da manhã é iluminada pelo sol" e "a estrela da tarde é iluminada pelo sol", o "pensamento" muda mas a referência é a mesma (op. Cit., p.67). Qual a referência de uma sentença? A referência das sentenças, para Frege, consiste no Verdadeiro e no Falso, isto é, em sua conexão com o real, as circunstâncias em que são verdadeiras ou falsas. Esta é uma das teses de Frege mais questionadas por seus críticos, que dirão que se a referência de uma sentença é o Verdadeiro ou o Falso, todas as sentenças verdadeiras teriam a mesma referência.

A determinação da referência de um nome ou expressão descritiva envolve a possibilidade de determinar a verdade da sentença, o fato de que há um objeto correspondente. Não podemos especificar o significado dos termos interdependentemente da formulação de sentenças. Apenas um "pensamento" (conteúdo de uma expressão predicativa) pode ser verdadeiro ou falso. $\mathrm{O}$ sentido de uma sentença é portanto o "pensamento", o que afirmamos ou negamos, sendo assim algo de objetivo, independente da intenções do falante.

Por exemplo, ao ter que perguntar sobre as horas para alguém, porque desconfia que o relógio do celular está atrasado, ao 
invés de simplesmente perguntar e agradecer - mesmo frente quanto à uma resposta negativa ríspida - sem justificar, rapidamente o mitômano cria uma desculpa. Como não usa relógio e confere as horas no celular, ele pode então alertar, com a pessoa ainda verificando as horas, ou que o seu celular descarregara, ou o relógio do celular ficara maluco. A pessoa diz as horas, de bom grado, e, aliviado, o sujeito mente, rindo, procura ser o mais agradável possível: "Não falei? Tá louquinho." A hora informada pela pessoa bate com a que seu celular indicava. Qual o motivo disso? O fato real, a verdade não alivia mitômano. Além de que há o temor de que a pessoa fique incomodada com sua interpelação sobre as horas e seu mundo desabe mesmo que a resposta não seja abruptamente uma resposta mal-educada. Aliás, para esse sujeito, a grande maioria das pessoas está contra ele. O que leva a deduzir que sua mentira pode ser uma maneira revanchista de se socializar. Aqui se vê a desestrutura do superego, senão sua ausência.

\section{Como frisa Ivan Capelatto:}

[...] O dano perverso da ausência do superego. É um ego frágil que não resiste ao conflito das pulsões, as pulsões precisam ser realizadas de qualquer maneira e o outro, quem é o outro para quem não tem superego? O outro é aquele que me lesa. O outro é aquele que lesa. Então, não importa quem seja o outro, meu pai, minha mãe, meu irmão, meu vizinho, o estranho na rua, o anônimo, o menino que está pendurado no carro - o caso do menino João Hélio. O fato de o outro existir significa é o fato de que me falta alguma coisa. $\mathrm{O}$ relógio que o outro tem é o motivo de tristeza e de raiva para mim. O corpo do outro, a casa do outro. E aí entra uma coisa que vocês vão, talvez, se horrorizar, que é muito usado dentro de alguns sistemas políticos: $\mathrm{Eu}$ sou pobre porque você é rico. Eu sou feio porque você é bonito. Eu não tenho esse relógio porque você tem. Eu sou baixo porque você é alto. Eu sou negro porque você é branco. Não sei se vocês entendem o que eu estou falando. Esse é o discurso da ausência de superego. Esse é o discurso da ausência de superego. O discurso que passeia pela miséria das favelas, o discurso que passeia pela miséria dos condomínios fechados [...]

$\mathrm{O}$ princípio ativo da mentira era sempre o mesmo, a langorosa autoestima o impedindo de agir para garantir não se "ferir" por uma resposta negativa, uma crítica, já que para o mitômano pouca coisa nele é quão boa nos outros, e ele termina por se deprimir mais ainda, o desejo de se mitificar fica reprimido por conta de sua inação. A imaginação tem que dar cabo desse seu vazio. O quero, posso e devo sempre conflitante.

E quanto mais mente mais o mitômano se encoraja a mentir, melhor fica no engendramento dessas mentiras. A despeito disso, como já escrevi, não se recorre às mentiras apenas para enganar as pessoas à sua 
volta. É que, com isso, e enquanto isso, apesar das mentiras parecerem - e são - alienadas, lhe atribuem admiração em vez de chacota, um alívio maior e mais duradouro do sofrimento de seu vazio e autodesprezo.

E esse sujeito já tomara cerveja em São Paulo com esse ou aquele o filósofo, o ator, o psicólogo, o escritor, o antropólogo, pois seus parentes frequentam aquele meio e o inseria inevitavelmente quando ia lá.

No fundo, o mitômano não se importa com o outro, aprendeu isso em sua infância. Ivan Capelatto, acima, explicou bem a respeito do dano causado a essa criança que desse modo age quando preconiza que se a criança consegue fazer mal à mãe, pessoa tão íntima, e ir dormir, então ela pode fazer o mundo chorar. Tem o poder de abolir o mundo. Pior, se acha nesse direito.

Contudo, como qualquer viciado, à certa altura se começa a mentir não pelo prazer - do alívio - que isso trazia mas, simples e obrigatoriamente, para abrandar o sofrimento do mal estar entre uma mentira e outra.

Se nascer era mesmo um inconvenientemente como propunha Cioran, o mitômano pode comprovar isso dispensando filosofia, psicologia, psiquiatria, psicanálise ou religião. Mesmo o senso comum diz que os tímidos precisam de cesariana até para viver. $\mathrm{E}$, pela vida continuam precisando que lhe abram o caminho para passar - ou mesmo estagnar. Se isso não ocorre, se tornam hospedeiros de alguma outra planta como uma Bromélia que se aninha a uma árvore para conseguir mais luz, se nutrir e "hidratar" melhor - como quem precisa de empurrões e muitas garantias de que encontrará seu lugar ao sol. Piormente podem se tornar parasitas sugando o outro mesmo como se o outro lhe devesse isso sem nada em "troca". Quando esses dois aspectos não lhe são possibilitados, a única saída em meio aos muitos não enxergados é se encantoarem até se deprimirem e, às vezes, por fim se matarem.

Para Becker:

[...] quanto menos você faz, menos pode fazer, mais desamparado e dependente você se torna. Quanto mais se esquiva das dificuldades e das ousadias da vida, mais naturalmente passa a sentir-se inepto, menos favorável é a sua autoavaliação. Isso é inelutável. Se a vida de uma pessoa tem sido uma série de "silenciosos recuos", ela acaba inapelavelmente encurralada em um canto e não tem mais para onde recuar. Esse estado é o emperramento da depressão.

\section{O desmascaramento do mitômano e o inevitável e crucial tratamento}

Vamos supor, aqui, um sujeito que, além de cesariana, precisou de que lhe evitassem uma espécie de suicídio. Tal como inúmeros bebês, devido ao estreitamento da bacia, ele nascera entre a cor roxa e a violeta. Custara a respirar - se é que respira hoje em dia. Sua ansiedade pode se explicar por uma 
garra imaginária que permanece pressionando sua cabeça, que faz lhe faltar ar ou the proporciona a mesma sensação angustiante, a falta.

Vamos ilustrar, revisitar essa sensação com a passagem onde um mitômano é acareado quanto a mentir.

Relutante com o convite de um colega, o sujeito topa tomar umas e outras num bar depois da aula, do trabalho. Detalhe: devido às frequentes recusas os colegas e as colegas não mais o convidavam. Lá, após umas cervejas, o indivíduo começa a falar que ia entrar com um projeto na Fapemig e estava para publicar um dos seus ensaios por uma editora francesa. Após uma pausa silenciosa, desentende o primeiro sorriso - de escarninho ou de entusiasmo? - do colega, que bate a cinza do cigarro no cinzeiro, tranquilamente. Este diz que seu interlocutor, era gente boa, mas mentiroso. $\mathrm{O}$ sujeito sente o rosto ruborizar, sente a mesma rejeição de quando descobriu que a mãe o abandonara no mundo com a tia, o pai verdadeiro não era seu padrasto alcoólatra. Era incontrolável. Ainda que sentisse o chão fugir de seus pés, ainda que soubesse que poderia mesmo se inscrever com um projeto, publicar um ensaio, era mentira, mas, procura reverter a situação, rebate que ele brincava com muita coisa mesmo, mas estava com um projeto... O colega intervém novamente rindo mais alto e, quando se controla, arremata com um desdenho recalcitrante: "Isso é bom". E fita fixamente sei interlocutor. Este não vê a hora de sair dali. Nota pena por parte do outro.

O seu indevassável mundo criado fora devassado, devastado. Ainda àquela noite, elaboraria um projeto e o enviaria de fato às editoras, instituições científicas e etc., ao passo que elaboraria o ensaio dos ensaios num único texto e nem que pagasse o publicaria. Por outro lado se frustra por tornar consciente que era realmente um mentiroso inveterado.

Esse pensamento carregado de raiva faz com que o individuo mitômano veja que possui uma ideia distorcida a respeito das pessoas. Ou generaliza fatos isolados de sua infância na vida adulta. Como nunca tivera nada do que pedira naquele tempo e ainda que esperneasse tivesse seus pedidos de ajuda para se alimentar e se manter limpo adiados ou recusados, igualmente não poderia os atender agora.

Começa a se dar conta de que o mundo é não ríspido, mas só mundo, tudo concretamente tácito e repetitivo. Há mesmo somente alguns tipos de pessoas. A realidade começa a lhe invadir dolorosamente, precisa escrever sobre aquilo, aquela dor no peito, precisa mentir quanto ao mundo. Que apesar de tudo o mundo é belo e ele o grande responsável por aquilo, aliás, um dos grandes responsáveis, ninguém pode dar um sentido diferente senão ele. Mas qual sentido? E se não quisesse dar sentido algum se quisesse simplesmente viver aquilo, viver aquilo o quê? 
Freud, fala a respeito do sentimento oceânico:

[...] Nosso presente sentimento do ego não passa, portanto, de apenas um mirrado resíduo de um sentimento muito mais inclusivo - na verdade, totalmente abrangente -, que corresponde a um vínculo mais íntimo entre o ego e o mundo que o cerca. Supondo que há muitas pessoas em cuja vida mental esse sentimento primário do ego persistiu em maior ou menor grau, ele existiria nelas ao lado do sentimento do ego mais estrito e mais nitidamente demarcado da maturidade, como uma espécie de correspondente seu. Nesse caso, o conteúdo ideacional a ele apropriado seria exatamente o de ilimitabilidade e o de um vínculo com o universo - as mesmas ideias com que meu amigo elucidou o sentimento ‘oceânico'.

\section{E Caio Garrido o explica:}

Existem certas condições psíquicas existentes nos indivíduos que são geradas e guiadas por um contorno especial, trazido como se fosse uma memória afetiva dos tempos glórios e inglórios da relação com a mãe, no período compreendido desde o enovelamento narcísico no útero da mãe, até a concepção, a amamentação, o desmame, e todas as outras formas de separações inevitáveis que vão ocorrendo ao longo da vida. Rompimentos ou vivências que possam ter acontecido de forma demasiadamente abrupta ou com sofrimento (toda separação é um sofrimento), podem acarretar uma série de complicações psíquicas ao humano.

"De perto, ninguém é normal", disse Caetano. Para mim, o indivíduo não passa realmente de uma fabricação social.

\section{José Avzaradel escreve:}

[...] A sociedade impõe a forma social do indivíduo ao lhe propor e impor uma outra origem e outra modalidade de significado; a significação imaginária social, a identificação midiatizada com esta (suas articulações), a possibilidade de tudo reportar a ela. A questão do significado deveria assim, saturar-se, encerrando-se a procura da psique. Mas, de fato, isso nunca acontece. De uma lado, o indivíduo socialmente fabricado (por mais sólido e estruturado que seja) não é estável, não é aquisição vitalícia, não é nada mais do que uma película encobrindo o caos, o abismo, o sem fundo, a infinitude, que não permite nunca uma outra forma de enunciarse e apresentar-se a ela. De outro lado, o significado ou sua ausência é sempre uma decorrência da experiência emocional, ou uma função de amor-próprio, ódio próprio ou conhecimento próprio. Não é necessário logicamente, mas psicologicamente.

O sujeito que sofre de mitomania pode alguma vezes ter que, além de uma intervenção psicológica, também medicamentosa para a ansiedade, a depressão. 


\section{Leo Branco escreve:}

O tratamento para a doença envolve atendimento psicológico e, em alguns casos, medicamentos antidepressivos para elevar a autoestima do paciente.

O alprazolam é um antidepressivo, usado nesses casos, porém no início, o paciente ainda fica entre os picos da depressão e da ansiedade, para só então se estabilizar.

Paciente anônima:

A consciência da doença fez meu mundo imaginário sumir e lidar com a realidade para quem tem essa doença é as vezes bem difícil, os remédios tem me ajudado um pouco, me deixa um pouco mais calma.

Termina-se, de certo modo, domado pelo remédio como que sendo adestrado - e realmente está. $\mathrm{O}$ intuito é agir como agiria depois que se pare com os medicamentos, seja dispensado do processo terapêutico. Ainda que possa haver recaídas ligeiras, com o tratamento, as mentiras começam a se aproximar bem das mentiras "essenciais" da sociedade, até que evolua-se para uma acentuada melhora dos sintomas ou mesmo o seu total desaparecimento.

Outrossim, não há um tempo de resposta determinado que se possa generalizar quanto ao tratamento. Isso varia de paciente para paciente.

\section{REFERÊNCIAS}

${ }^{1}$ Arnaldo Chuster, Linguagem e Construção

do Pensamento, p. 131, Editora Casa do

Psicólogo, $2^{\circ}$ Edição, 2006

${ }^{2}$ Becker, Ernest, A Negação da Morte, p. 65, Editora Record, Rio de Janeiro,1973.

${ }^{3}$ Becker, Ernest, A Negação da Morte, p. 19, Editora Record, Rio de Janeiro, 1973.

${ }^{4}$ Becker, Ernest A Negação da Morte, p. 207, Editora Record, Rio de Janeiro,1973.

${ }^{5}$ Caio Garrido,

http://psiqueativa.blogspot.com.br/

${ }^{6}$ Cioran, Emil Do Inconveniente de Ter Nascido, por Salvador Massano Cardoso: http://quartarepublica.blogspot.com.br/2010/1 0/do-inconveniente-de-ter-nascido.html

${ }^{7}$ Benilton Bezerra, As Novas Fronteiras da Subjetivção https://www.youtube.com/watch?v=AwOIzQ7Oi $\underline{w E}$

${ }^{8}$ Danilo Marcondes, Linguagem e Construção do Pensamento, p. 32, Editora Casa do Psicólogo, $2^{\circ}$ Edição, 2006

${ }^{9}$ Freud, Sigmund, O Futuro de uma Ilusão, O mal-estar na civilização e outros trabalhos VOLUME XXI, p. 43. (1927-1931) http://www.psicanaliseflorianopolis.com/artig os/147-obras-completas-de-sigmundfreud.html

${ }^{10}$ Ivan Capelatto, Limites: A Formação necessária do superego https://www.youtube.com/watch?v=Lf7SeEfy s8 
${ }^{11}$ Leo Branco:

http://mdemulher.abril.com.br/bem-

estar/reportagem/viver-bem/precisei-

tratamento-pra-parar-mentir-584261.shtml

${ }^{12}$ http://curandoapseudolalia.blogspot.com.br/

2012/12/efeito-dos-medicamentos.html

${ }^{13} \mathrm{http} / / /$ curandoapseudolalia.blogspot.com.br/

2012/12/o-inicio-do-tratamento.html 